\title{
Joint Impact of Scaling and Hysteresis on NAPL Flow Simulation
}

\author{
Hung-Hui Chen • Liang-Cheng Chang $•$ Hsin-Yu Shan • \\ Jui-Pin Tsai
}

Received: 10 September 2007 / Accepted: 27 August 2008/Published online: 25 November 2008

(C) Springer Science + Business Media B.V. 2008

\begin{abstract}
The hysteresis of capillary pressure versus saturation $(P-S)$ relation is an important constitutive relation in multiphase flow, since the $P-S$ relation is widely used to predict $P-S$ relations in the simulation of the non-aqueous phase liquids (NAPLs). This work examined the performance of the scaling rule on predicting the $P-S$ relationship and then studied the joint impact of the scaling and hysteresis on the multiphase NAPL flow simulation. Various experimental $P-S$ values of distinct fluid pairs were compared with the scaled $P-S$ curves using the scaling rule. The comparison indicated that the prediction of $P-S$ is more accurate when the water-air $P-S$ curve is used to scale other $P-S$ curves. The joint impact of the scaling and hysteresis on the NAPLs flow simulation was then investigated by numerical simulation studies. The NAPL simulator was used to simulate the outcome of several scenarios based on a system with water-NAPL-air in a hypothetical sand tank. For both gasoline and trichloroethylene, the difference of the injected NAPL volume between no hysteretic and hys-
\end{abstract}

\footnotetext{
H.-H. Chen

Department of Civil Engineering,

Min Hsin University Science Technology,

Hsinchu, Taiwan

e-mail: j1203035@must.edu.tw

L.-C. Chang $(\bowtie) \cdot$ H.-Y. Shan $\cdot$ J.-P. Tsai

Department of Civil Engineering,

National Chiao Tung University,

Hsinchu, Taiwan

e-mail: lcchang@chang.cv.nctu.edu.tw

H.-Y. Shan

e-mail: hyshan@mail.nctu.edu.tw

J.-P. Tsai

e-mail: Skysky2cie@gmail.com
}

teretic simulations over a given time period was the smallest when the water-air $P-S$ curve was used to scale other $P-S$ curves. Simulation results of this study are valuable references for predicting the distribution of NAPLs.

Keywords NAPL $\cdot$ Hysteresis $\cdot$ Scaling rule

\begin{tabular}{|c|c|}
\hline \multicolumn{2}{|l|}{ Notation } \\
\hline$a_{\mathrm{d}}$ & $\begin{array}{l}\text { the curve shape fitting parameter for } \\
\text { water drainage curves } \\
\text { (dimensionless) }\end{array}$ \\
\hline$a_{\mathrm{i}}$ & $\begin{array}{l}\text { the curve shape fitting parameter for } \\
\text { water imbibition curves } \\
\text { (dimensionless) }\end{array}$ \\
\hline$f$ & $\begin{array}{l}\text { the curve type index, takes on a } \\
\text { value from } 1 \text { to } 6\end{array}$ \\
\hline$k$ & intrinsic permeability scale $\left(L^{2}\right)$ \\
\hline$k_{\mathrm{r} \alpha}$ & $\begin{array}{l}\text { the relative permeability of the } \alpha \\
\text { phase, } \alpha=W, N, G \text { (dimensionless) }\end{array}$ \\
\hline$m$ & $\begin{array}{l}\text { a fitting parameter used in the } \\
k_{\mathrm{r}}-S-P \text { model (dimensionless) }\end{array}$ \\
\hline$S_{\mathrm{e}}$ & $\begin{array}{l}\text { the effective wetting-phase satura- } \\
\text { tion for a given } P-S \text { curve }\end{array}$ \\
\hline$S_{\mathrm{e}(f)}$ & $\begin{array}{l}\text { the effective wetting-phase satura- } \\
\text { tion for a specific } P-S \text { curve type } f\end{array}$ \\
\hline$S_{\mathrm{eW}}, S_{\mathrm{eN}}, S_{\mathrm{eG}}$ & $\begin{array}{l}\text { the effective saturation used to } \\
\text { define of the } k_{\text {ra }} \text { function of water, } \\
\text { NAPL, and air, respectively }\end{array}$ \\
\hline$S_{\mathrm{Wr}}, S_{\mathrm{Nn}}, S_{\mathrm{Gr}}$ & $\begin{array}{l}\text { residual saturation for water, NAPL, } \\
\text { and air, respectively }\end{array}$ \\
\hline$S_{\mathrm{Nwt}}$ & $\begin{array}{l}\text { total wetting saturation in a NAPL- } \\
\text { air system }\end{array}$ \\
\hline$S_{\mathrm{Nnr}}$ & $\begin{array}{l}\text { a curve fitting parameter represent- } \\
\text { ing the maximum NAPL-phase re- } \\
\text { sidual saturation in a }\end{array}$ \\
\hline
\end{tabular}




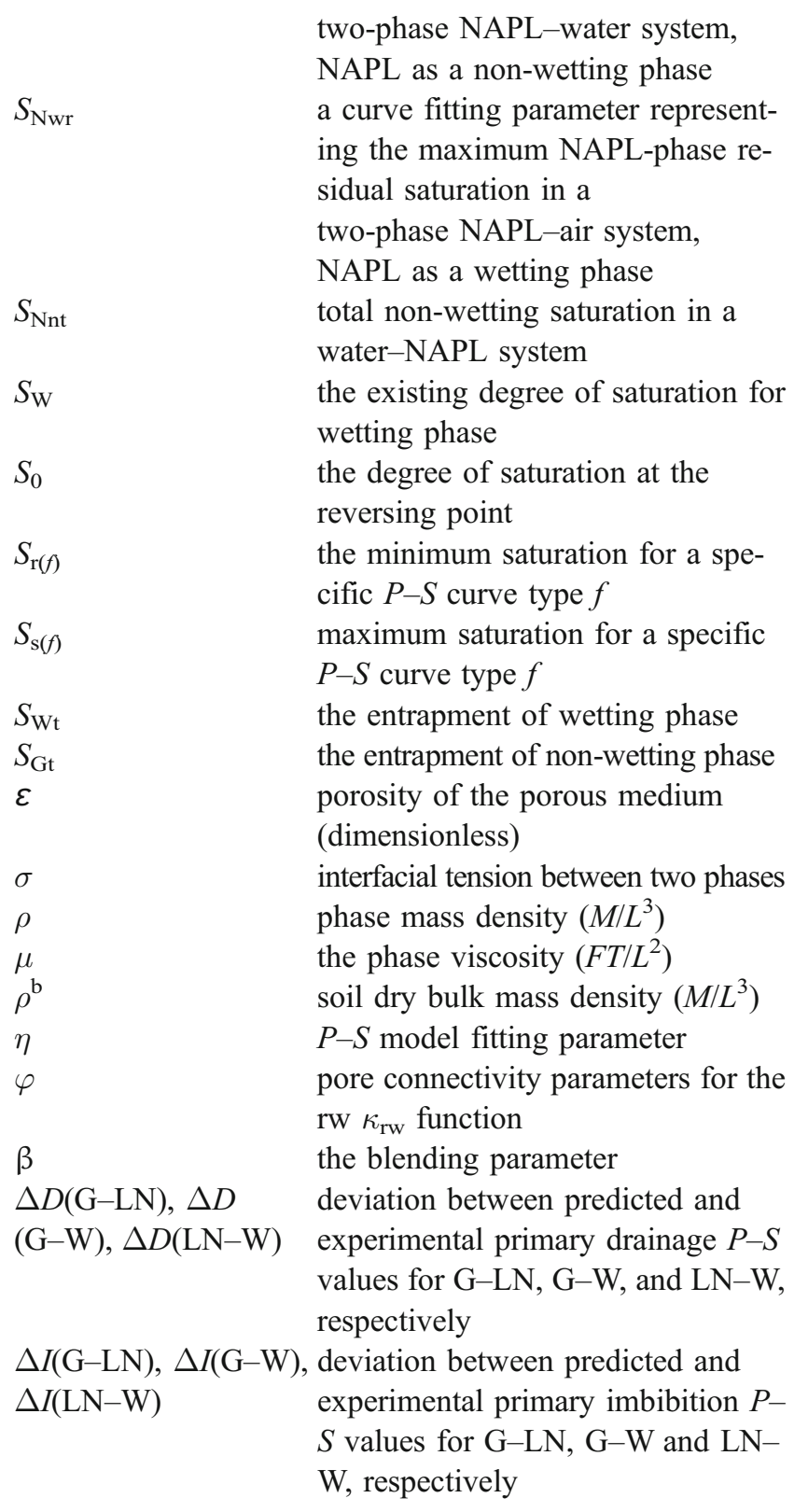

\section{Introduction}

The contamination of groundwater by organic solvents, such as trichloroethylene (TCE), tetrachloroethylene (PCE), and other petroleum-based products has raised considerable concern because of its serious threat to human health. Most of these organic solvents are in liquid form in the subsurface with low solubility in water and are called non-aqueous phase liquids (NAPLs). These NAPLs or their solutions, even at low concentrations, can have severely adverse effects on human health over the long term [1]. Some of the NAPLs are trapped in the soil pores as they move downward and are known as residuals. Because
NAPL flow in the subsurface is a complicated process, Kuppusamy et al. [11] and Mercer and Cohen [15] utilized numerical simulation to evaluate the total volume and flow of contaminants under various assumed conditions. They demonstrated that numerical simulation is useful for testing assumptions regarding parameters and boundary conditions. Moreover, in numerical simulation of NAPL flow, capillary pressure versus saturation $(P-S)$ curves are critical constitutive law and must be specified before computation. The hysteresis and scaling rule are two important aspects of the $P-S$ curve. Hysteresis is a common feature of a $P-S$ curve for any multiphase system in soil. The scaling rule is an important theorem in predicting unknown $P-S$ curves. For a three-phase system (water-NAPL-air), it is difficult to measure the $P-S$ values directly when the three phases coexist simultaneously. Researchers have suggested the use of two-phase relations to estimate three-phase ones in a three-phase system [18]. Although $P-S$ curves associated with two-phase fluid pairs (water-NAPL, NAPL-air, water-air) are required for characterizing the $P-S$ relations and simulating NAPL flow in the three-phase system, obtaining the experimental $P-S$ curves for all the fluid pairs is time-consuming. Parker et al. [18] proposed a scaling rule to predict the $P-S$ curve of a fluid pair based on that of another fluid pair. Although the scaling rule is convenient to use and has facilitated the simulation of NAPL flow, Faust and Guswa [3] demonstrated that the field conditions are much more complex than those considered in linear scaling and therefore limit the applications of the scaling rule in the field. Fagerlund et al. [2] compared the performance of applying a different relative permeabilitysaturation-capillary pressure $(K-S-P)$ model for simulating NAPL migration. Their results show that although there are differences between predictions based on the different models, all models exhibit some common problems, and it is not obvious that any one model is more accurate than another one. For NAPLs, no exact theory currently exists for scaling two-phase capillary pressure-saturation functions to three-phase systems. Fagerlund et al. [2] indicated that the NAPL-gas capillary pressure-saturation function had the strongest influence on NAPL migration and the scaling procedure should focus on improving the accuracy of this function. Kool and Parker [10] and Kaluarachchi and Parker [8] indicated that the deviations in the predicted NAPL flow were significant without considering hysteresis, especially for three-phase systems. Van Geel and Roy [24] proposed a model to incorporate a residual NAPL saturation into an existing hysteretic three-phase parametric model developed by Lenhard and Parker [13]. Their proposed model is similar in form to the entrapment model proposed by Parker and Lenhard, a model based on an expression presented by Land [12]. Their study indicated that the formation of a residual NAPL saturation in the 
Step 1:

Use the experimental data of selected fluid-pair as the reference P-S curve

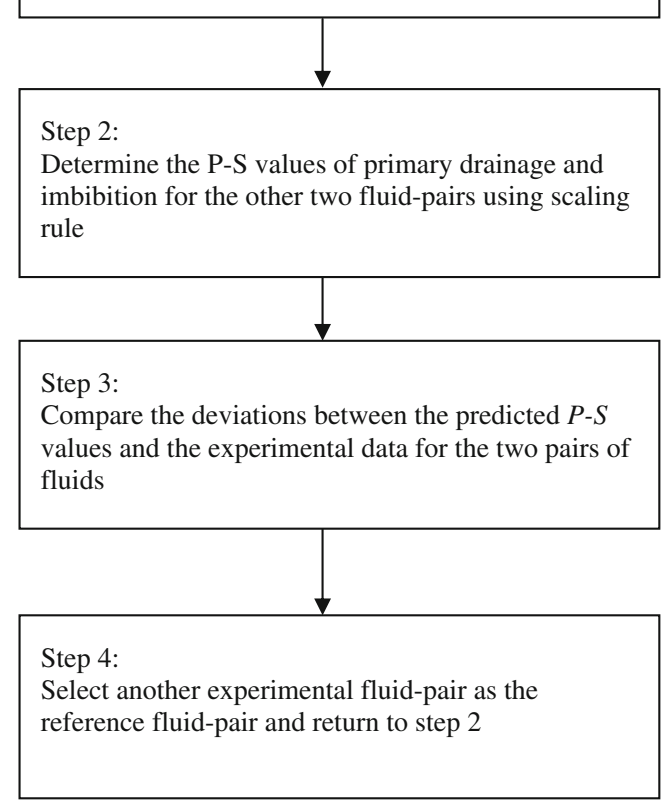

Fig. 1 Procedure for examining performance of scaling rule for various reference fluid pairs

unsaturated zone was an important process to include in the hysteretic constitutive relationships used to model multiphase flow. Zhang and Smith [26] had successfully conducted experiments of PCE penetration into watersaturated porous media in a two-dimensional transparent tank. They found that the PCE fingers propagated into the water-saturated zone through a winding route predominately downward. Kechavarzi et al. [9] performed a twodimensional laboratory simulation of the light non-aqueous liquid (LNAPL) infiltration and redistribution in the vadose zone. However, those paper did not consider scaling effect and hysteresis influence in simulating NAPL flow.
An equation to describe $K-S-P$ relationship is necessary for multi-phase flow simulation. Various formulations representing the $K-S-P$ relationship have been proposed by researchers. Among them, the $K-S-P$ equation proposed by Van Genuchten [25] is widely used and adopted in the NAPL Simulator. The classical independent domain theory introduced by Everett marked a milestone in the field of adsorption [21]. Everett's independent domain theory of sorption hysteresis was presented in a series of publications between 1952 and 1955. The main assumption of the theory visualized the porous network as an assemblage of independent pores whose behavior during the capillary process did not depend on each other. Hysteresis was recognized at the level of one pore and extended to the level of the whole network through the summation of individual pore hysteretic contributions, which was similar to the $K-S-P$ model approach based on Van Genuchten [25].

Recent research [22] indicates that Parlange [20] contributed greatly to the development of the flow equation theory. The solutions to the Parlange model are highly dependent upon the form of the relationships between the water content, the matric potential (head), and the unsaturated hydraulic conductivity. Mualem [16] presented a universal scanning relationship between the main drying and wetting curves, which was similar to the Parlange [19] model, and the NAPL simulator's approach based on Van Genuchten [25] when assuming the distribution functions of water in the pore domains for drying and wetting are the same for the independent domain model. Haverkamp et al. [7] presented an experimental study of hysteresis phenomenon to assess the performance of three predictive hysteresis models. For the sands (fine, coarse, and silt sand) studied, hysteresis effect can be clearly observed and should not be ignored. Their results also indicate that the Parlange model allows good predictions of the main drying curves. Flynn et al. [4] used the van Genuchten equation [25] to formulate a Preisach model that had a nickname "wedge

Table 1 Sum of root mean squares deviations between predicted and experimental $P-S$ values for fluid pairs: gasoline-air (LN-G), water- air (W-G), and water-gasoline (W-LN)

\begin{tabular}{|c|c|c|c|c|c|c|c|c|}
\hline \multirow{2}{*}{$\begin{array}{l}\text { Reference } \\
\text { fluid pairs }\end{array}$} & \multicolumn{8}{|c|}{ Deviations between predicted and experimental $P-S$ values for examined fluid pairs } \\
\hline & $\begin{array}{l}\Delta D(\mathrm{LN}-\mathrm{G}) \\
(\mathrm{cm})\end{array}$ & $\begin{array}{l}\Delta I(\mathrm{LN}-\mathrm{G}) \\
(\mathrm{cm})\end{array}$ & $\begin{array}{l}\Delta D(\mathrm{~W}-\mathrm{G}) \\
(\mathrm{cm})\end{array}$ & $\begin{array}{l}\Delta I(\mathrm{~W}-\mathrm{G}) \\
(\mathrm{cm})\end{array}$ & $\begin{array}{l}\Delta D(\mathrm{~W}-\mathrm{LN}) \\
(\mathrm{cm})\end{array}$ & $\begin{array}{l}\Delta I(\mathrm{~W}-\mathrm{LN}) \\
(\mathrm{cm})\end{array}$ & $\begin{array}{l}\text { Sum of deviations } \\
\text { for drainage } \\
\text { and imbibition, } \\
\text { respectively }(\mathrm{cm})\end{array}$ & $\begin{array}{l}\text { Sum of deviations } \\
\text { including drainage } \\
\text { and imbibition }(\mathrm{cm})\end{array}$ \\
\hline$D(\mathrm{LN}-\mathrm{G})$ & & & 3.28 & & 3.62 & & 6.90 & 10.78 \\
\hline$I(\mathrm{LN}-\mathrm{G})$ & & & & 0.82 & & 3.06 & 3.88 & \\
\hline$D(\mathrm{~W}-\mathrm{G})$ & 1.14 & & & & 0.83 & & 1.97 & 4.10 \\
\hline$I(\mathrm{~W}-\mathrm{G})$ & & 0.20 & & & & 1.93 & 2.13 & \\
\hline$D(\mathrm{~W}-\mathrm{LN})$ & 1.69 & & 1.19 & & & & 2.88 & 6.12 \\
\hline$I(\mathrm{~W}-\mathrm{LN})$ & & 1.19 & & 2.05 & & & 3.24 & \\
\hline
\end{tabular}


Table 2 Sum of root mean squares of deviations between predicted and experimental $P-S$ values for fluid pairs: TCE-air (DN- G), water-air $(\mathrm{W}-\mathrm{G})$, and water-TCE $(\mathrm{W}-\mathrm{DN})$

\begin{tabular}{|c|c|c|c|c|c|c|c|c|}
\hline \multirow{2}{*}{$\begin{array}{l}\text { Reference } \\
\text { fluid pairs }\end{array}$} & \multicolumn{8}{|c|}{ Deviations between predicted and experimental $P-S$ values for examined fluid pairs } \\
\hline & $\begin{array}{l}\Delta D(\mathrm{LN}-\mathrm{G}) \\
(\mathrm{cm})\end{array}$ & $\begin{array}{l}\Delta I(\mathrm{LN}-\mathrm{G}) \\
(\mathrm{cm})\end{array}$ & $\begin{array}{l}\Delta D(\mathrm{~W}-\mathrm{G}) \\
(\mathrm{cm})\end{array}$ & $\begin{array}{l}\Delta I(\mathrm{~W}-\mathrm{G}) \\
(\mathrm{cm})\end{array}$ & $\begin{array}{l}\Delta D(\mathrm{~W}-\mathrm{LN}) \\
(\mathrm{cm})\end{array}$ & $\begin{array}{l}\Delta I(\mathrm{~W}-\mathrm{LN}) \\
(\mathrm{cm})\end{array}$ & $\begin{array}{l}\text { Sum of deviations } \\
\text { for drainage } \\
\text { and imbibition, } \\
\text { respectively }(\mathrm{cm})\end{array}$ & $\begin{array}{l}\text { Sum of deviations } \\
\text { including drainage } \\
\text { and imbibition }(\mathrm{cm})\end{array}$ \\
\hline $\begin{array}{l}D(\mathrm{DN}-\mathrm{G}) \\
I(\mathrm{DN}-\mathrm{G})\end{array}$ & - & - & 2.00 & - & 0.93 & - & 2.93 & 2.93 \\
\hline $\begin{array}{l}D(\mathrm{~W}-\mathrm{G}) \\
I(\mathrm{~W}-\mathrm{G})\end{array}$ & 1.52 & & & & 0.09 & $\begin{array}{l}- \\
1.14\end{array}$ & $\begin{array}{l}1.61 \\
1.14\end{array}$ & 2.75 \\
\hline $\begin{array}{l}D(\mathrm{~W}-\mathrm{DN}) \\
I(\mathrm{~W}-\mathrm{DN})\end{array}$ & 0.91 & & 0.27 & 2.02 & & & $\begin{array}{l}1.18 \\
2.02\end{array}$ & 3.20 \\
\hline
\end{tabular}

model". The study showed that their model fits empirical data better than other model does with less parameter.

The above discussion indicates that hysteresis and the scaling rule are important in simulating NAPL flow. Hence, this study adopts experimental data from Shan and Wang [23] to examine the accuracy of the $P-S$ curve prediction using the scaling rule. Furthermore, this research also adopted NAPL simulator [6] to simulate the outcome of several scenarios based on a system with water-NAPL-air in a hypothetical sand tank and to investigate the joint impact of hysteresis and the scaling rule on the simulation of NAPL flow.

\section{Relevant Theorems}

To facilitate the description of the research procedure and results, some of the important relevant theorems are presented below.

\section{1 $P-S$ Curve and Scaling Rule}

NAPL simulator applied the van Genuchten model [25] that was similar to Parlange model [20] for simulating soilwater hysteresis of multiphase fluid system. The van Genuchten model is represented in Eq. 1.

$S=\left[1+(\alpha P)^{1 / 1-m}\right]^{-m}$

where $S$ is the degree of saturation for the wetting phase, $P$ is the capillary pressure head, and $\alpha$ and $m$ are empirical parameters.

Parker and Lenhard [17] further suggested that for multiphase fluids in a porous medium, the ratio of the capillary pressure equals the ratio of the interfacial tensions for any two fluid pairs.

$\frac{P_{c N W}}{\sigma_{N W}}=\frac{P_{c G N}}{\sigma_{G N}}=\frac{P_{c G W}}{\sigma_{G W}}$.
In Eq. 2, the scaling rule, $p_{\text {cIJ }}$ represents the capillary pressure between fluid I and fluid $\mathrm{J}$ and $\sigma_{\mathrm{IJ}}$ denotes the interfacial tensions between them. The indices $\mathrm{J}$ and I may be air $(\mathrm{G})$, NAPL $(\mathrm{N})$, and water $(\mathrm{W})$. Lenhard and Parker [13] indicated that a characteristic curve, a $P-S$ curve, of a fluid pair could be computed by scaling the experimental characteristic curves of another fluid pair based on Eq. 2 .

This scaling approach essentially presumes that the capillary tube model (Laplace-Young equation) is valid without considering the effect of the contact angle when scaling monotonic imbibition and drainage paths [9].

\subsection{Representation of Hysteresis in NAPL Simulator}

This work employed the NAPL simulator [6] to simulate the multiphase flow of NAPLs in porous media. The NAPL simulator solved a set of coupled nonlinear partial differential equations by combining fundamental balance equations with constitutive and thermodynamic relationships. The basic assumption of the NAPL simulator is still that all

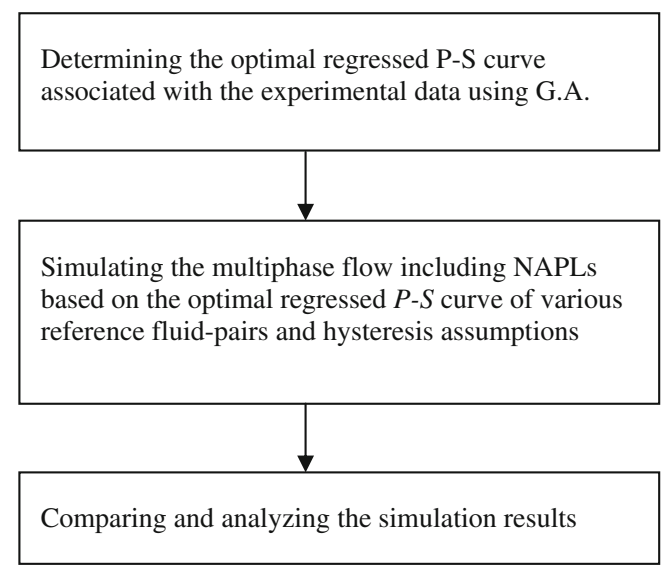

Fig. 2 Procedure for investigating the joint effect of hysteresis and scaling on simulating NAPL flow 
Fig. 3 Boundary condition for gasoline-water-air simulation

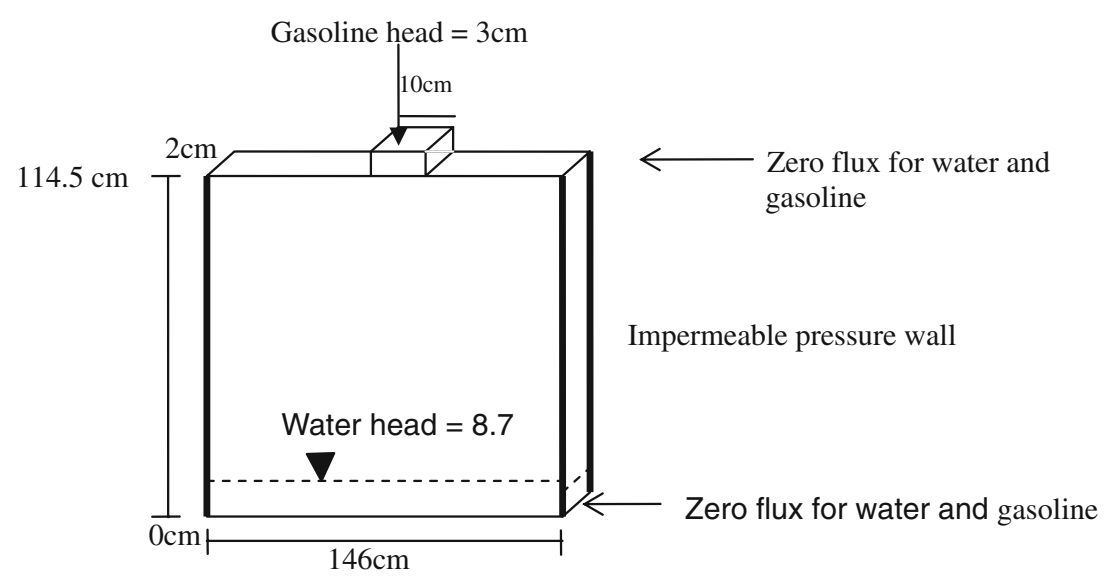

the parameters and variables are in the average sense and are spatially continuous. However, the fingering effect is discontinuous in space. Therefore, NAPL simulator cannot be directly applied to simulate the fingering effect without further assumptions.

Two constitutive relations, saturation-capillary pressure $(P-S$ curve $)$ and relative permeability-saturation $(K-S$ curve), simultaneously defined the multiphase relative permeability-saturation -capillary pressure $(K-S-P)$ relationship in the NAPL simulator.

The scanning curves are expressed as Eqs. 3 and 4 and are used in the NAPL simulator.

$$
\begin{aligned}
& h_{c(f)}=\left[\left(S_{e_{(f)}}\right)^{-1 / m}-1\right]^{1 / \eta}\left(a_{(f)}\right)^{-1} \\
& S_{e(f)}=\frac{S_{w}-S_{r(f)}}{S_{s(f)}-S_{r(f)}}, 0 \leq S_{e(f)} \leq 1
\end{aligned}
$$

where $h_{c}=p_{\mathrm{c}} / \sigma_{\mathrm{w}} g$ is the capillary pressure head and $m=1$ $-1 / \eta$ is the empirical parameter in the Van Genuchten equation. The subscript (f) specifies a particular curve type; $f$ refers to a drainage curve (SDCn) when it is odd and an imbibition curve (SICn) when it is even. Luckner et al. [14] indicated that the $K-S$ relationship for each phase was written as Eqs. 5, 6, and 7, respectively, for a watergasoline-air system. The equations are assumed valid for any wetting/non-wetting phase system in the NAPL simulator. It includes hysteresis as the result of fluid entrapment effects. In addition, it utilizes parameters from the $P-S$ sub-model, the parameter, and includes three fitting parameters, $\zeta, \varphi$, and $\varepsilon$.

$K_{r W}\left(S_{W}\right)=\left(S_{e W}\right)^{\zeta}\left\{1-\left[1-\left(S_{e W}\right)^{1 / m}\right]^{m}\right\}^{2}$

$K_{r G}\left(S_{G}\right)=\left(S_{e G}\right)^{\varphi}\left\{1-\left[1-\left(S_{e G}\right)^{1 / m}\right]^{m}\right\}^{2}$

$K_{r N}\left(S_{W}, S_{G}\right)=\left(S_{e N}\right)^{\varepsilon}\left\{\left[1-\left(1-S_{e T n}\right)^{1 / m}\right]^{m}-\left[1-\left(1-S_{e T w}\right) 1 / m\right]^{m}\right\}^{2}$

where $S_{\mathrm{eTn}}$ and $S_{\mathrm{eTw}}$ represent the effective total saturation of the non-wetting phase and wetting phase, respectively.

Fig. 4 Boundary condition for TCE-water-air simulation

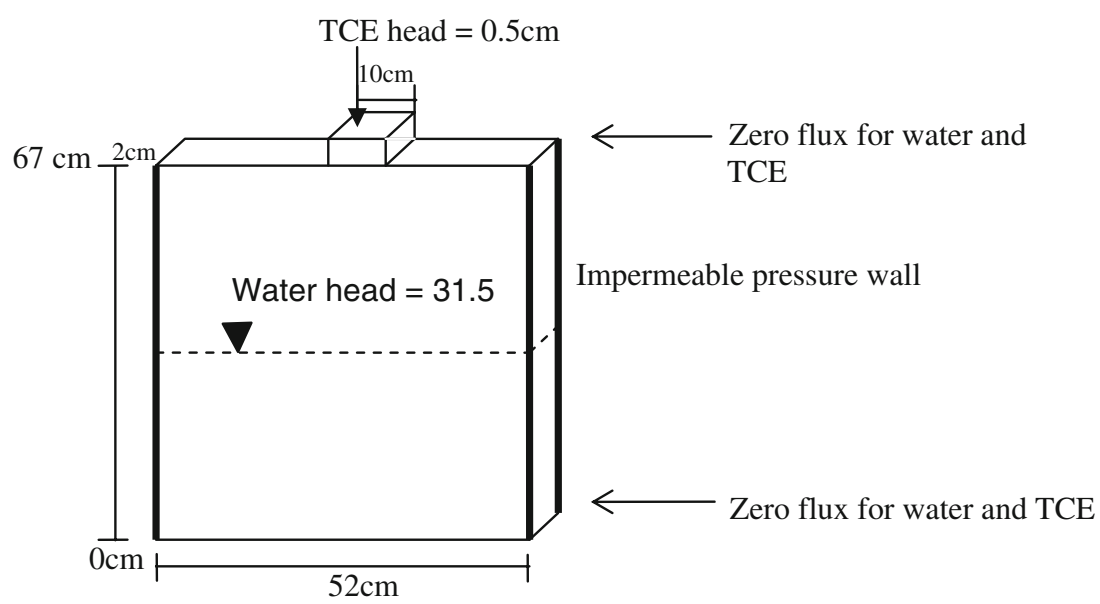


Table 3 Parameter values used in the gasoline (LNAPL) simulations

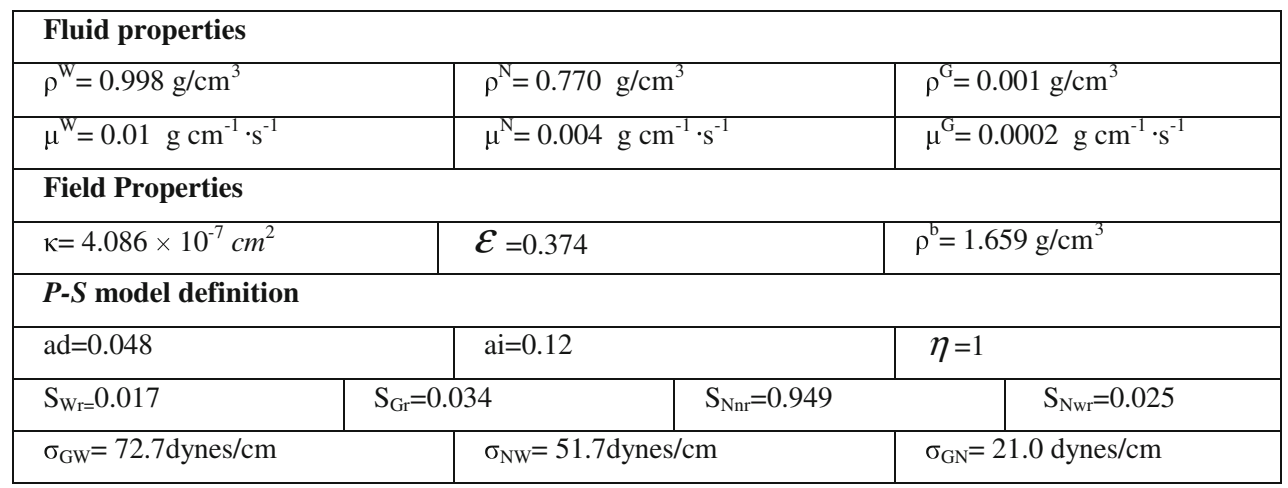

\section{Evaluating Performance of the Scaling Rule}

Figure 1 depicts the procedure for evaluating the performance of the scaling rule on predicting the $P-S$ values of various fluid pairs. The scaling rule was employed in the NAPL simulator and many other simulation models. The performance of the scaling rule in predicting the $P-S$ curve based on a reference fluid pair is important to NAPL simulation. For a water-air-NAPL system, based on the experimental data of a fluid pair, the scaling rule can predict the $P-S$ values of the other two fluid pairs. This study compared the scaled $P-S$ values of primary drainage and imbibition with the experimental $P-S$ data to evaluate the prediction performance of the scaling rule. The study used the experimental data from Shan and Wang [23] for various fluid pairs, including water-air, water-gasoline, gasolineair, and water-TCE. The experiments used a modified Tempe pressure cell-1400 from the Soil Moisture Company in the USA.

For a water-gasoline-air system, Table 1 presents the sum of the root mean square of the deviations between the experimental $P-S$ curve and the predicted $P-S$ curve using the scaling rule. Using the experimental $P-S$ curve of a fluid pair as a reference curve, one can predict the $P-S$ curves for the other two fluid pairs using Eq. 2. Therefore, each fluid pair has three $P-S$ curves: one is the experimental $P-S$ curve and the others are predicted by the experimental $P-S$ curves of other fluid pairs. For each fluid pair, the deviations between the experimental $P-S$ curve

Table 4 The boundary conditions of the gasoline-water-air modeling

\begin{tabular}{ll}
\hline Boundary domain & Specified condition \\
\hline Top boundary & Zero flux for water and gasoline \\
Bottom boundary & $h_{\text {water }}=8.7 \mathrm{~cm}$, zero flux for gasoline \\
Lateral boundary & Zero flux for water and gasoline \\
\hline
\end{tabular}

and predicted $P-S$ curves were evaluated. This study separately compared the primary drainage and primary imbibition for each fluid pair.

The second row in Table 1 shows the deviations between the experimental values and the predicted ones for the primary drainage of water-air $\Delta D(\mathrm{~W}-\mathrm{G})$ and watergasoline $\Delta D(\mathrm{~W}-\mathrm{LN})$. The predicted values were scaled by the experimental primary drainage $P-S$ value of gasoline-air $D(\mathrm{LN}-\mathrm{G})$. The deviations between the predicted primary drainage $P-S$ values and the experimental primary drainage $P-S$ values for the water-air $(\mathrm{W}-\mathrm{G})$ and water-gasoline (W-LN), found in columns $\Delta D(\mathrm{~W}-\mathrm{G})$ and $\Delta D(\mathrm{~W}-\mathrm{LN})$, were 3.28 and $3.62 \mathrm{~cm}$, respectively.

In the third row of Table 1 , columns $\Delta I(\mathrm{~W}-\mathrm{G})$ and $\Delta I$ (W-LN) show the deviations between the predicted primary imbibition $P-S$ values and the experimental primary imbibition $P-S$ values for water-air (W-G) and watergasoline $(\mathrm{W}-\mathrm{LN})$ as 0.82 and $3.06 \mathrm{~cm}$, respectively. The predicted values were scaled by the experimental primary imbibition $P-S$ values of gasoline-air, $I(\mathrm{LN}-\mathrm{G})$.

Similarly, the values in the other rows quantify the deviations between the predicted $P-S$ values and the experimental $P-S$ values for other examined fluid pairs based on the water-air $(\mathrm{G}-\mathrm{W})$ or water-gasoline $(\mathrm{LN}-\mathrm{W})$ reference pair.

Table 5 Summary of the modeling durations and conditions for gasoline-water-air

\begin{tabular}{lrl}
\hline $\begin{array}{l}\text { Simulation } \\
\text { step }\end{array}$ & Duration (s) & Condition \\
\hline Step 1 & $0-63,000$ & $\begin{array}{l}\text { Water was drained from full saturation } \\
\text { and no gasoline existed }\end{array}$ \\
Step 2 & $63,000-64,120$ & $\begin{array}{c}\text { Continuing from 63000 sec with the } \\
\text { gasoline source in the top boundary } \\
\text { (with 10 cm wide) } \\
\text { Continuing from step 2 and removing } \\
\text { the gasoline source }\end{array}$ \\
Step 3 & $64,120-66,000$ & \\
\hline
\end{tabular}


Table 6 Comparisons of infiltrating gasoline mass obtained with and without hysteresis (injection time $=1120 \mathrm{~s}$ )

\begin{tabular}{lccc}
\hline Reference fluid pairs & $\begin{array}{c}\text { (a) Infiltrating mass } \\
\text { with hysteresis }(\mathrm{g})\end{array}$ & $\begin{array}{l}(b) \text { Infiltrating mass } \\
\text { without hysteresis }(\mathrm{g})\end{array}$ & $\begin{array}{l}\text { Percentage difference } \\
{[(b)-(a)] /(a) \times 100 \%(\%)}\end{array}$ \\
\hline G-LN (air gasoline) & 544.13 & 1199.37 & 120.42 \\
G-W (air water) & 730.36 & 866.18 & 18.60 \\
LN-W (gasoline water) & 561.16 & 725.54 & 29.29 \\
\hline
\end{tabular}

Table 7 Parameter values used in TCE (DNAPL) simulations

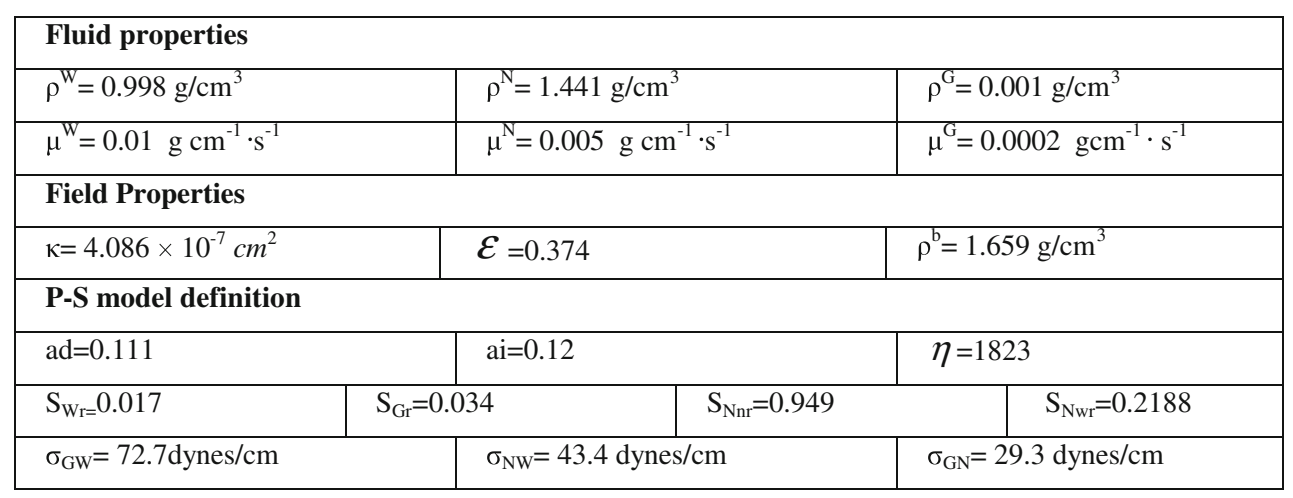

The last column in Table 1 presents the sums of the root mean square deviations based on the reference fluid pairs $\mathrm{W}-\mathrm{G}, \mathrm{W}-\mathrm{LN}$ and $\mathrm{LN}-\mathrm{G}$, including primary drainage and imbibitions, as $4.10,6.12$, and $10.78 \mathrm{~cm}$, respectively.

The results reveal that using the $\mathrm{W}-\mathrm{G}$ pair as the reference fluid pair yields the most reliable $P-S$ curve prediction of gasoline (LNAPL). Table 2 is similar to Table 1, but TCE (DN) replaces gasoline. Table 5 indicates that in three-phase systems that include TCE, the sum of the root mean square deviations was $2.75 \mathrm{~cm}$ when the $\mathrm{W}-\mathrm{G}$ pair was used as the reference pair. This was lower than those obtained using all other reference fluid pairs. Tables 1 and 2 show that if a reference fluid pair is required in a NAPL simulation, the water-air (W-G) pair should be selected. In Tables 1 and 2, the sum of root mean squares deviations between predicted and experimental $P-S$ values, $\Delta D(\mathrm{LN}-\mathrm{G})$ is defined as: $\Delta D(\mathrm{LN}-\mathrm{G})=\sqrt{\sum_{i=1}^{n}\left(h_{i}-\hat{h}_{i}\right)^{2}} / n$, where $h_{i}=\frac{p_{i}}{\gamma_{\mathrm{w}}}$ is the $i_{\mathrm{th}}$ experimental capillary pressure head $(\mathrm{cm}), \hat{h}_{i}$ is the $i_{\text {th }}$ predicted capillary pressure head using scaling rule $(\mathrm{cm}), \gamma_{\mathrm{w}}$ is specific weight of water, and $n$ is the number of data.

\section{Numerical Study}

Figure 2 depicts the procedure for studying the joint effects of hysteresis and scaling on NAPL flow simulation.
Genetic algorithm (GA) [5] was employed to obtain the optimal regressed $P-S$ curves of the two-phase experimental data as indicated in Fig. 1. The regressed $P-S$ curves were then employed in the NAPL simulator. Identifying the optimal parameters of the $P-S$ curve is a simple nonlinear regression problem which can be solved using various nonlinear algorithms. However, because of the convenience and robustness of GA, this study employed a simple GA to solve the parameter identification problem and compute the optimal regressed $P-S$ curves. Figure 2 shows the procedure for investigating the joint effect of hysteresis and scaling on simulating NAPL flow. The NAPL simulator uses the given $P-S$ curve of a reference fluid pair to estimate the $P-S$ curves of other two fluid pairs by scale rule. The three two-phase $P-S$ curves together define the three-phase $P-S$ curve.

The case studies were based on a hypothetical sand tank adopted from the NAPL simulator's document. Figures 3

Table 8 The boundary conditions of the TCE-water-air modeling

\begin{tabular}{ll}
\hline Boundary domain & Specified condition \\
\hline Top boundary & Zero flux for water and TCE \\
Bottom boundary & $h_{\text {water }}=31.5 \mathrm{~cm}$, zero flux for TCE \\
Lateral boundary & Zero flux for water and TCE \\
\hline
\end{tabular}


Table 9 Summary of the modeling durations and conditions for TCE-water-air

\begin{tabular}{lrl}
\hline $\begin{array}{l}\text { Simulation } \\
\text { step }\end{array}$ & Duration (s) & Condition \\
\hline Step 1 & $0-63,000$ & $\begin{array}{l}\text { Water was drained from saturation } \\
\text { and no TCE existed } \\
\text { Continuing from step 1 with the } \\
\text { TCE source in the top boundary } \\
\text { (with 10 cm wide) }\end{array}$ \\
Step 2 3 & $63,000-64,120$ & $\begin{array}{c}\text { Continuing from step 2 and removing } \\
\text { the TCE source }\end{array}$ \\
\hline
\end{tabular}

and 4 show the configuration of the sand tank used to simulate the multiphase flow of gasoline-water-air and TCE-water-air, respectively. The main simulation procedure proposed by this study was the following.

The porous medium was assumed saturated with water initially. (Water saturation) was one and (NAPL saturation) was zero.

Step 1 Following the initial assumption, this step simulates the drainage of water without NAPL resulting in water and air saturation. The assumed top boundary condition was zero flux and the bottom boundary was maintained at a constant water head to simulate the drainage of water through the tank bottom.
Step 2 This step simulated the migration of the NAPL source in an unsaturated porous medium. The boundary condition of water was the same as in step 1, while the boundary condition for NAPL was zero flux on the top and bottom boundary. A constant NAPL head with a specified width on the top boundary simulated a constant NAPL source.

Step 3 The boundary conditions for water and NAPL in step 2 were maintained and the NAPL source was removed. The migration of NAPL in porous media was simulated for a given period.

\subsection{Modeling Infiltration of LNAPL in Multiphase Flow (Case 1)}

The joint impact of hysteresis and the scaling rule on the simulation of gasoline (LNAPL) flow in the subsurface based on distinct reference fluid pairs, GN, GW, or NW, was examined. As shown in Fig. 3, the dimensions of the sandy tank were $114.5 \mathrm{~cm}$ deep by $146 \mathrm{~cm}$ wide by $2 \mathrm{~cm}$ thick for the gasoline-water-air case, and the gasoline source with $10 \mathrm{~cm}$ wide by $2 \mathrm{~cm}$ thick was specified as a constant head $\left(h_{\text {gasoline }}=3 \mathrm{~cm}\right)$ located at the middle of the tank. Table 3 presents the parameters used in this case. Table 4 describes the boundary conditions. The simulation follows the previous procedure and Table 5 summarizes the

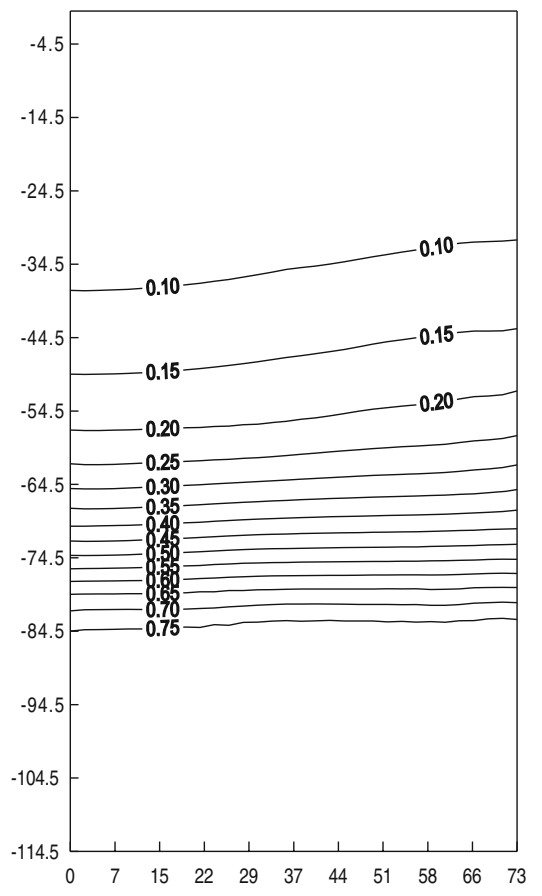

(a)

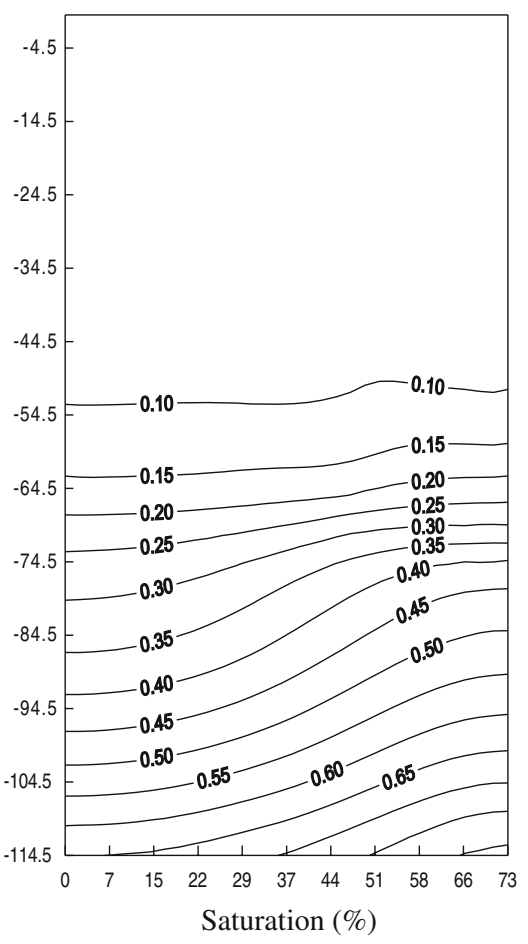

(b)

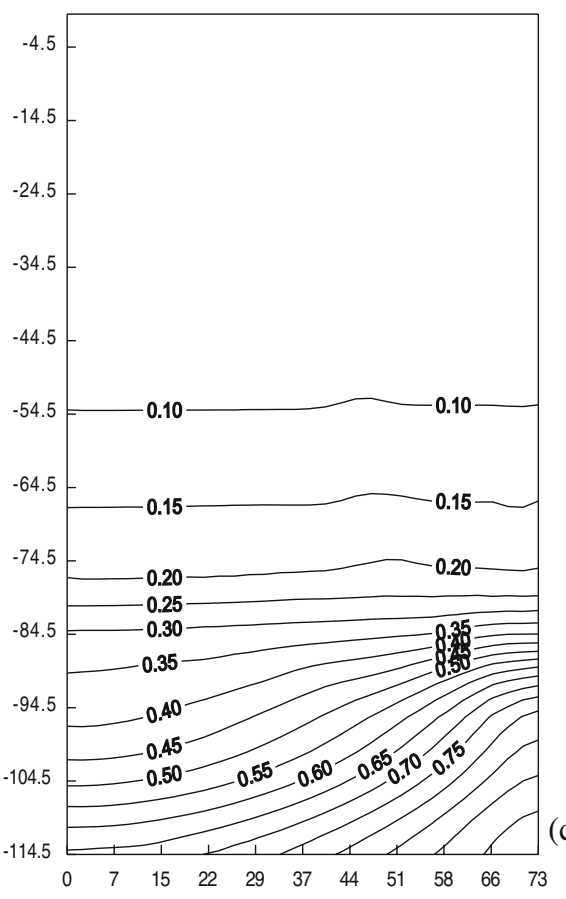

(c)

Fig. 5 Distribution of water saturation with hysteresis $(t=66,000 \mathrm{~s})$ and using G-LN (a), G-W (b), and LN-W (c) as reference pair 


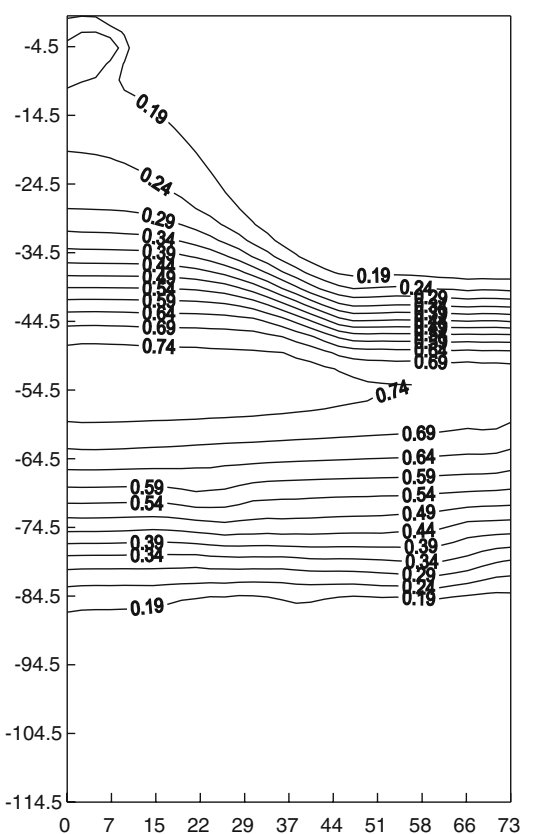

(a)

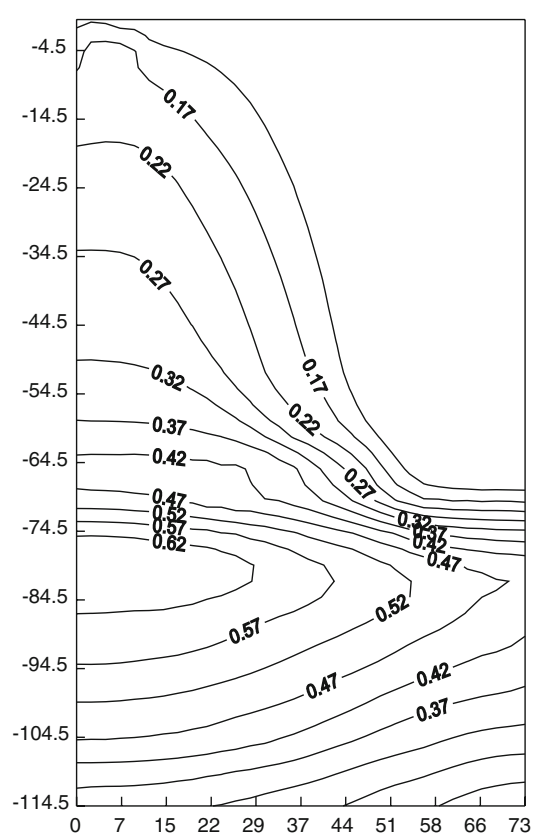

(b)

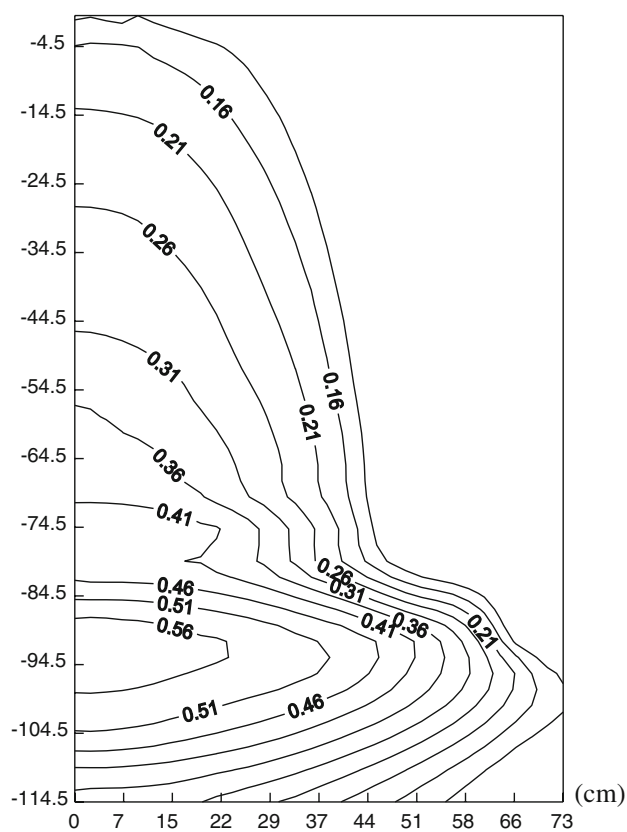

(c)

Fig. 6 Distribution of gasoline saturation with hysteresis ( $t-66,000 \mathrm{~s})$ and using G-LN (a), G-W (b), and LN-W (c) as reference pair

duration of each step and the conditions in the simulation. Only the $P-S$ curve for water-air $(\mathrm{G}-\mathrm{W})$ is required in step 1 , as no LNAPL is present in this step. In step 2 and step 3, the migration of gasoline was simulated and different reference fluid pairs were used in the simulation. For each reference fluid pair, two further distinct conditions, with and without hysteresis, were considered. Therefore, six numerical computations under distinct conditions were performed. Table 6 summarizes the resulting infiltrating mass of gasoline and is discussed in the next section.

\subsection{Modeling Infiltration of DNAPL in Multiphase Flow (Case 2)}

In case 2, the joint impact of hysteresis and the scaling rule on the simulation of TCE (DNAPL) flow in the subsurface

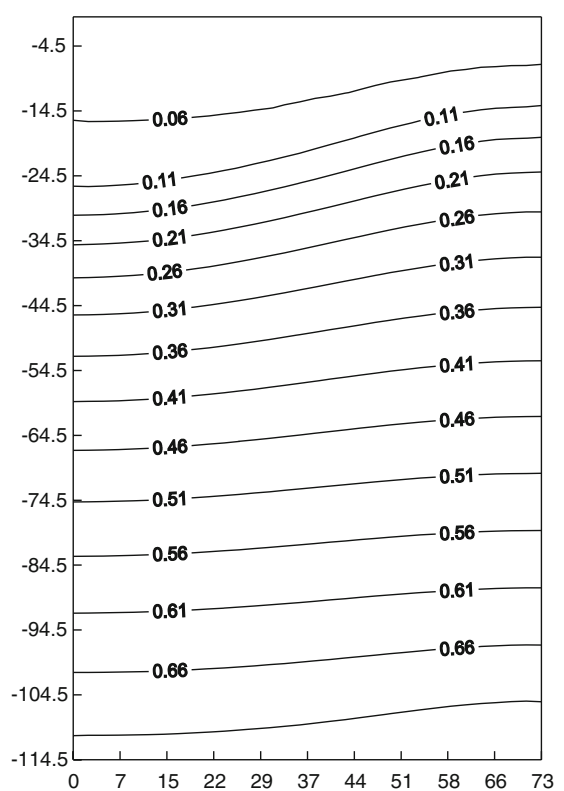

(a)

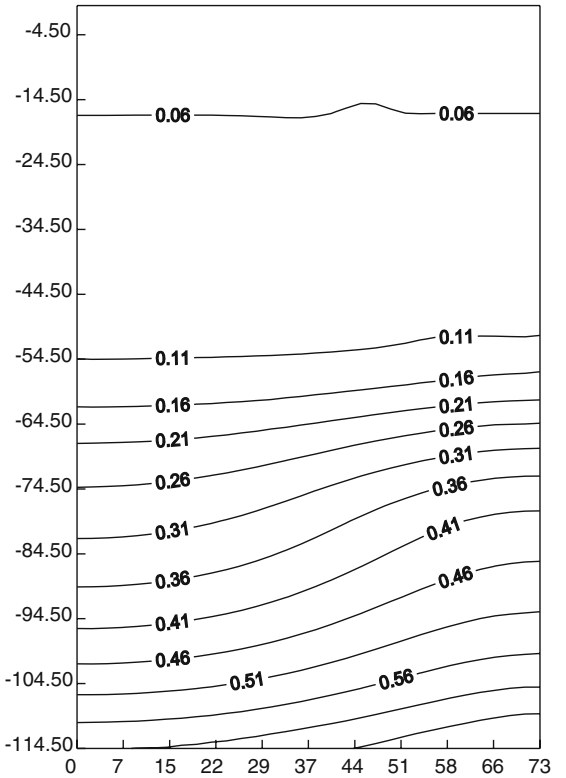

(b)

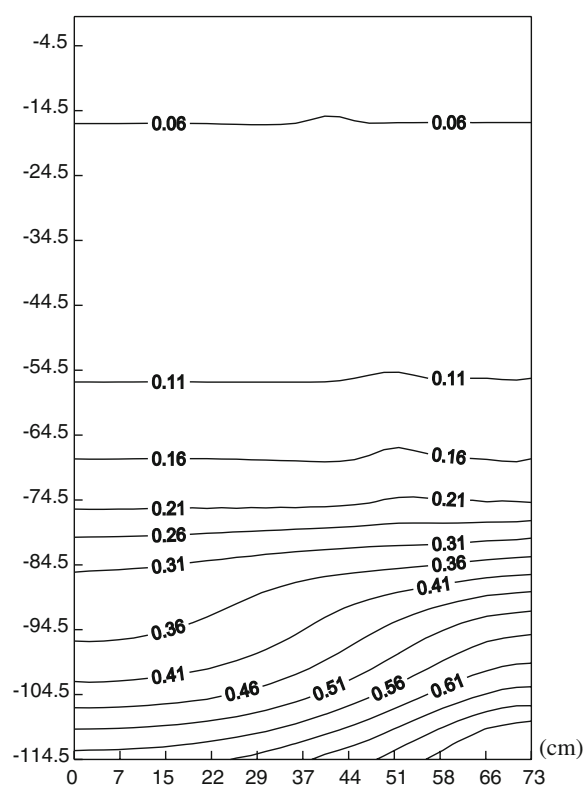

(c)

Fig. 7 Distribution of water saturation without hysteresis ( $t-66,000$ s) and using G-LN (a), G-W (b), and LN-W (c) as reference pair 


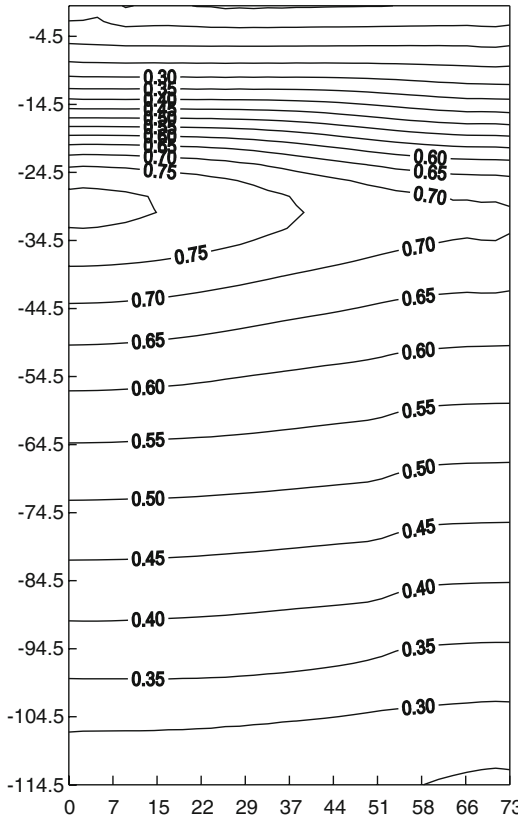

(a)

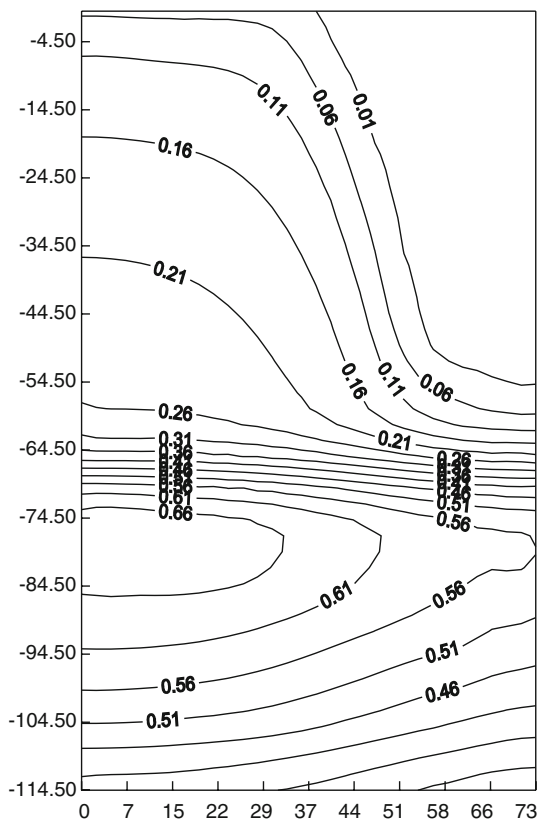

(b)

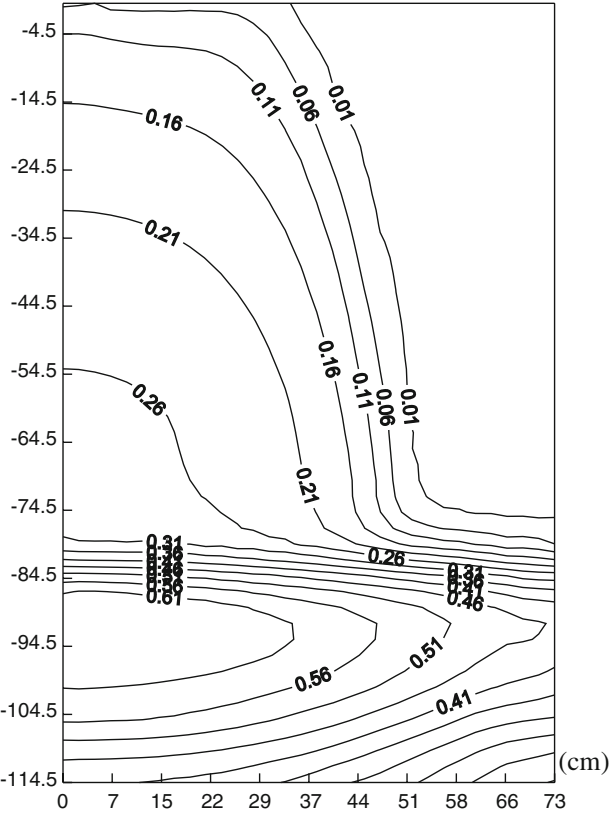

(c)

Fig. 8 Distribution of gasoline saturation without hysteresis $(t-66,000$ s) and using G-LN (a), G-W (b), and LN-W (c) as reference pair

was examined based on distinct reference fluid pairs DN$\mathrm{G}, \mathrm{W}-\mathrm{G}$, or $\mathrm{W}-\mathrm{DN}$. The dimensions of tank and TCE source were shown in Fig. 4. The TCE-water-air case was $67 \mathrm{~cm}$ deep by $52 \mathrm{~cm}$ wide by $2 \mathrm{~cm}$ thick and the TCE source was $10 \mathrm{~cm}$ wide by $2 \mathrm{~cm}$ thick was specified as a constant head $\left(h_{\mathrm{TCE}}=0.5 \mathrm{~cm}\right)$ located at the middle of tank. Table 7 presents the used parameters. The procedure is similar to that for case 1 , except that TCE replaced the

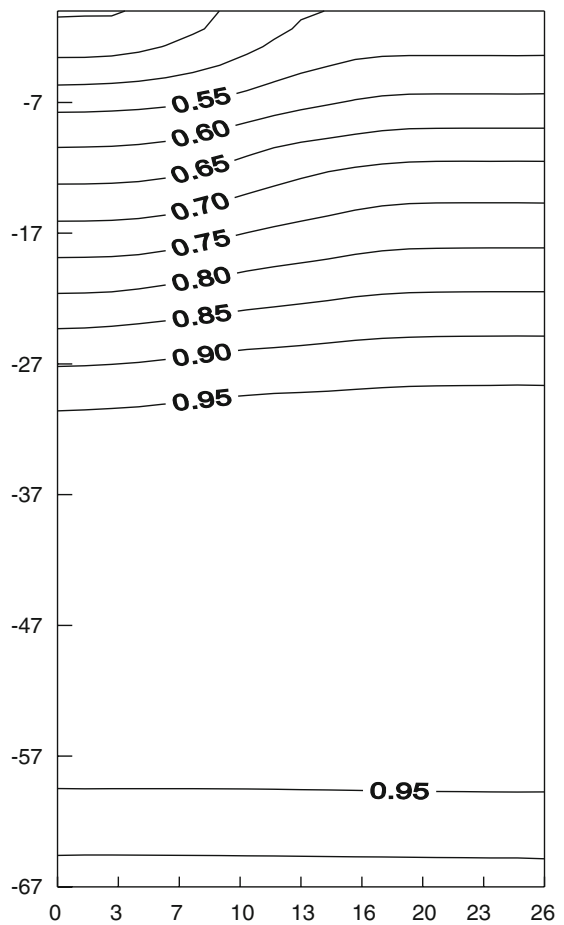

(a)

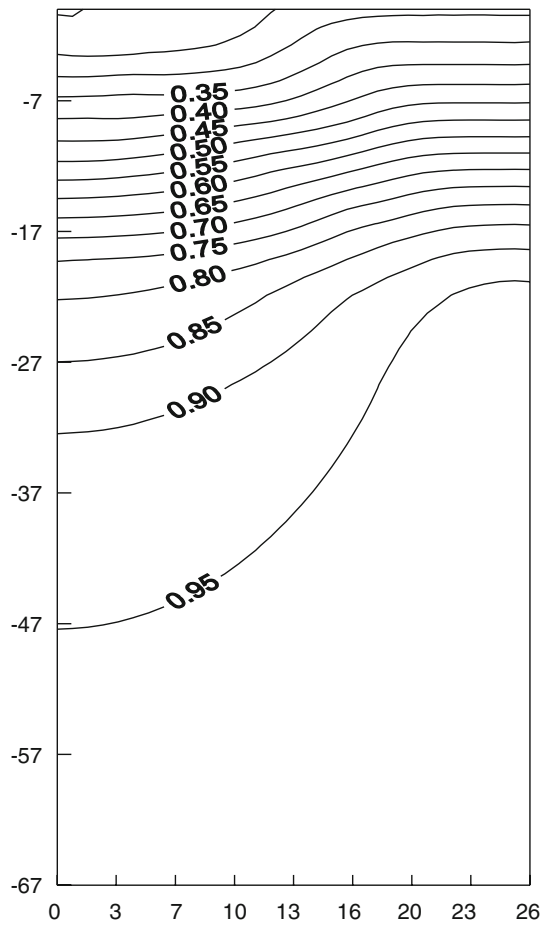

(b)

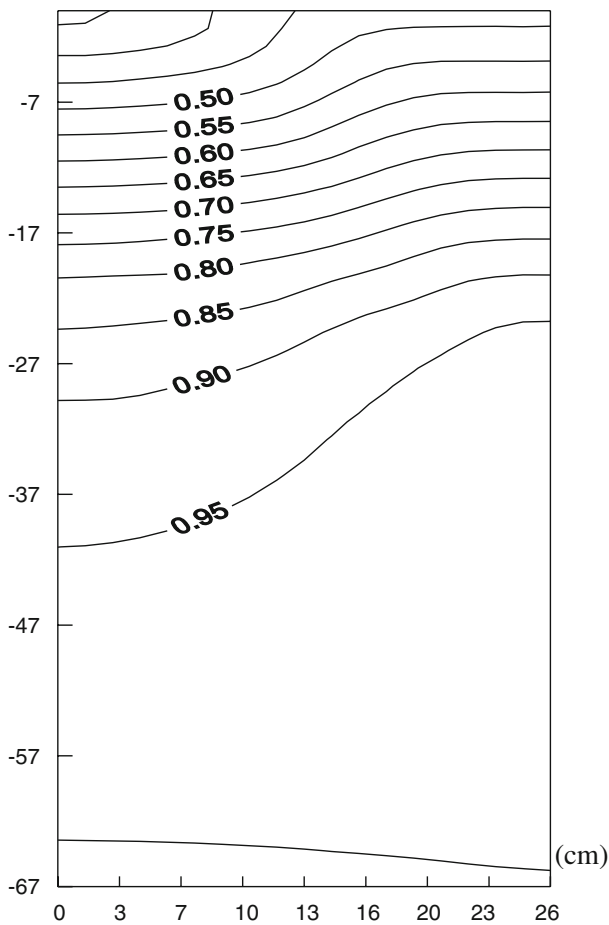

(c)

Fig. 9 Distribution of water saturation with hysteresis $(t-8,693 \mathrm{~s})$ and using G-DN (a), G-W (b), and DN-W (c) as reference pair 
Table 10 Comparisons of infiltrated TCE mass with and without hysteresis (injection time $=143 \mathrm{~s}$ )

\begin{tabular}{llll}
\hline Reference fluid- pairs & $\begin{array}{l}(a) \text { Infiltrated mass } \\
\text { with hysteresis }(\mathrm{g})\end{array}$ & $\begin{array}{l}(b) \text { Infiltrated mass } \\
\text { without hysteresis }(\mathrm{g})\end{array}$ & $\begin{array}{l}\text { Percentage difference } \\
{[(b)-(a)] /(a) \times 100 \%(\%)}\end{array}$ \\
\hline G-DN (air-TCE) & 32.92 & 64.60 & 96.23 \\
G-W (air-water) & 72.52 & 87.16 & 18.82 \\
DN-W (TCE-water) & 69.15 & 79.27 & 14.63 \\
\hline
\end{tabular}

gasoline. The boundary conditions are similar to case 1; only, the bottom water head is different. Table 7 presents the boundary conditions and Table 8 summarizes the duration of each step and the conditions in the simulation. Six numerical computations under distinct conditions were performed in this case. Table 9 summarizes the resulting infiltration mass of TCE and is discussed in the next section.

\section{Discussion}

Figures 5, 6, 7, 8, and 9 plot the distribution of water and gasoline saturation for various reference fluid pairs and hysteresis conditions at the end of the simulation $(66,000 \mathrm{~s})$. Table 6 summarizes the infiltrating gasoline mass in case 1 as described in the preceding section. The NAPL distribution and total mass that infiltrated into a hypothetical tank without hysteresis were compared to those with hysteresis. As shown in the last column of
Table 6, the gasoline mass was significantly larger without hysteresis for all three reference fluid pairs. The difference of the gasoline mass obtained with and without hysteresis was largest when the reference fluid pair was gasoline-air (LN-G). The infiltration gasoline mass obtained without hysteresis was $120.4 \%$ greater than that with hysteresis. The spatial distributions of gasoline in Figs. 6, 7, and 8 also demonstrate this phenomenon. Comparing Figs. 6 and 8 clearly reveals that the degree of saturation for gasoline without hysteresis exceeds that with hysteresis, and the difference is largest when gasoline-air ( $\mathrm{LN}-\mathrm{G})$ is used as the reference pair. Table 9 also demonstrates that using water-air $(\mathrm{W}-\mathrm{G})$ as the reference pair minimizes the difference of the TCE mass with and without hysteresis.

Table 10 summarizes the infiltrating TCE mass in case 2 as described in the previous section. Figures 9, 10, 11, and 12 plot the associated distribution of water and TCE saturation using various reference fluid pairs under various hysteresis conditions at the end of the simulation $(8,693 \mathrm{~s})$. Table 10 reveals that the TCE mass infiltrating into the

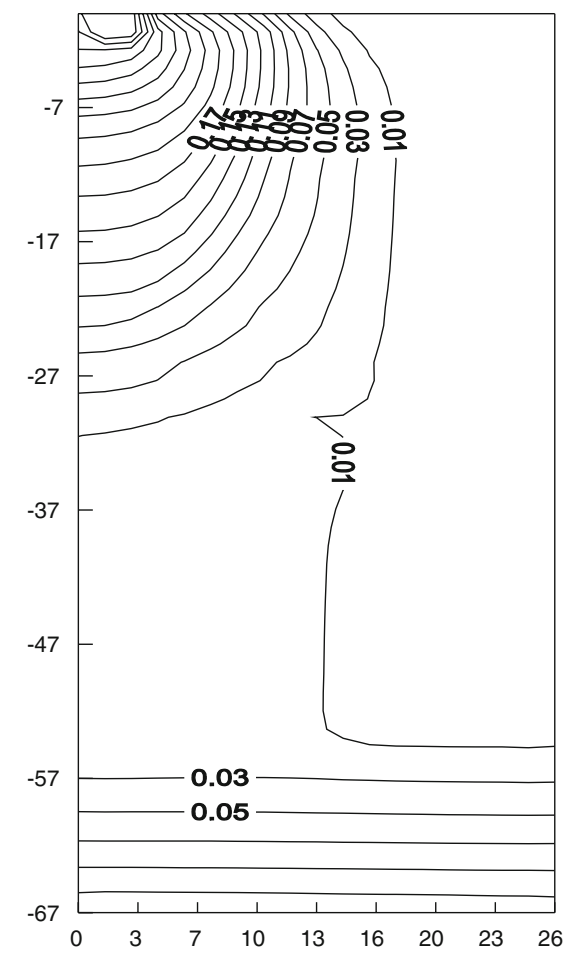

(a)

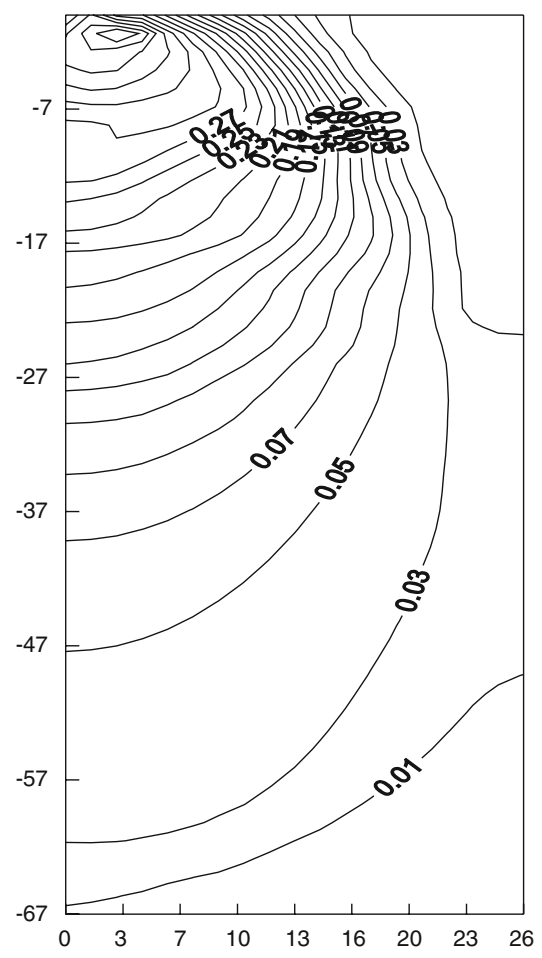

(b)

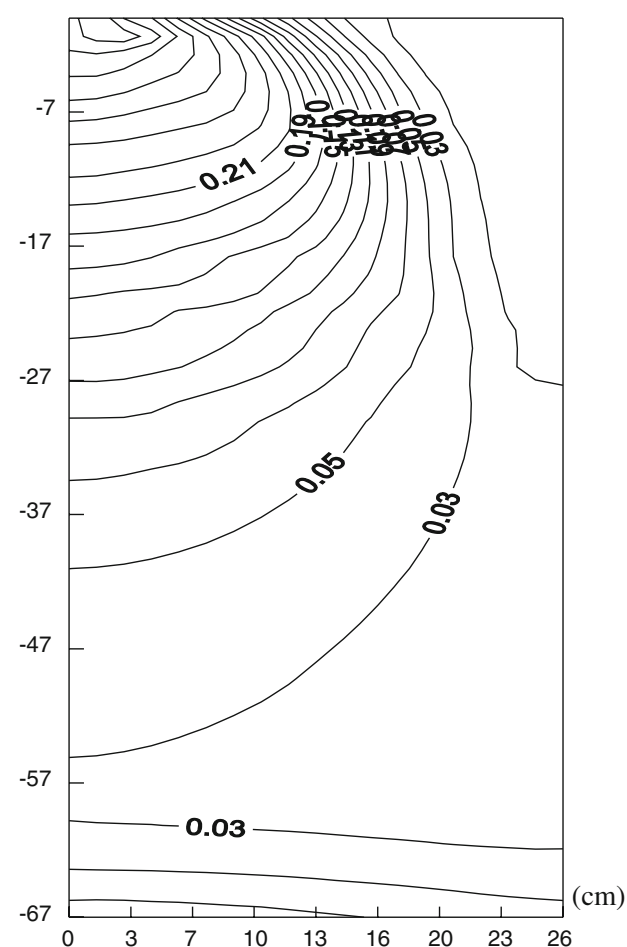

(c)

Fig. 10 Distribution of TCE saturation with hysteresis $(t-8,693 \mathrm{~s})$ and using G-DN (a), G-W (b), and DN-W (c) as reference pair 


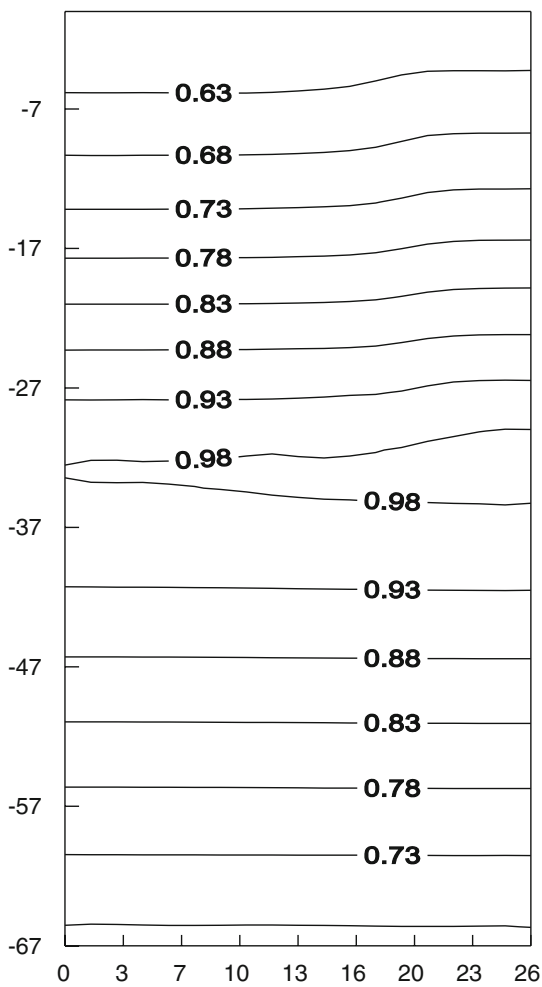

(a)

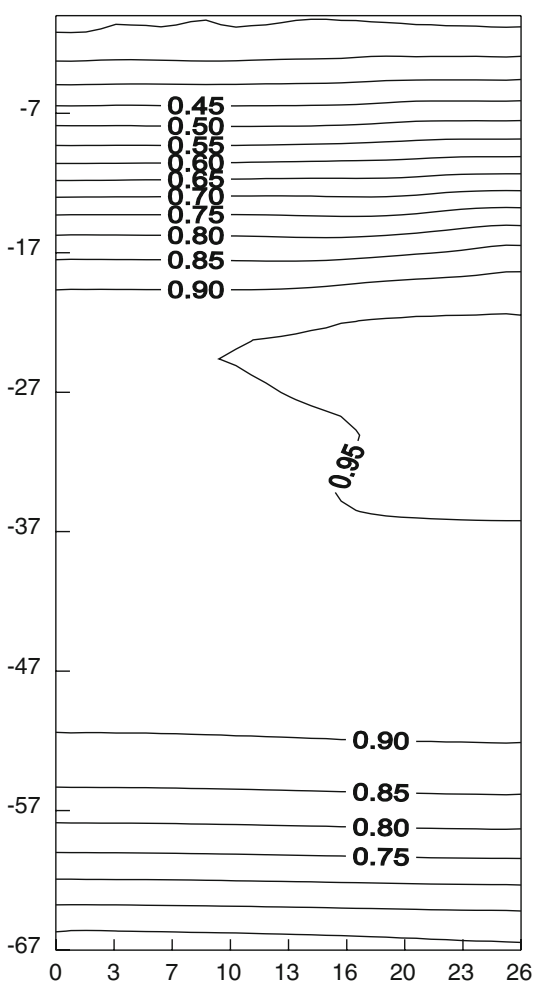

(b)

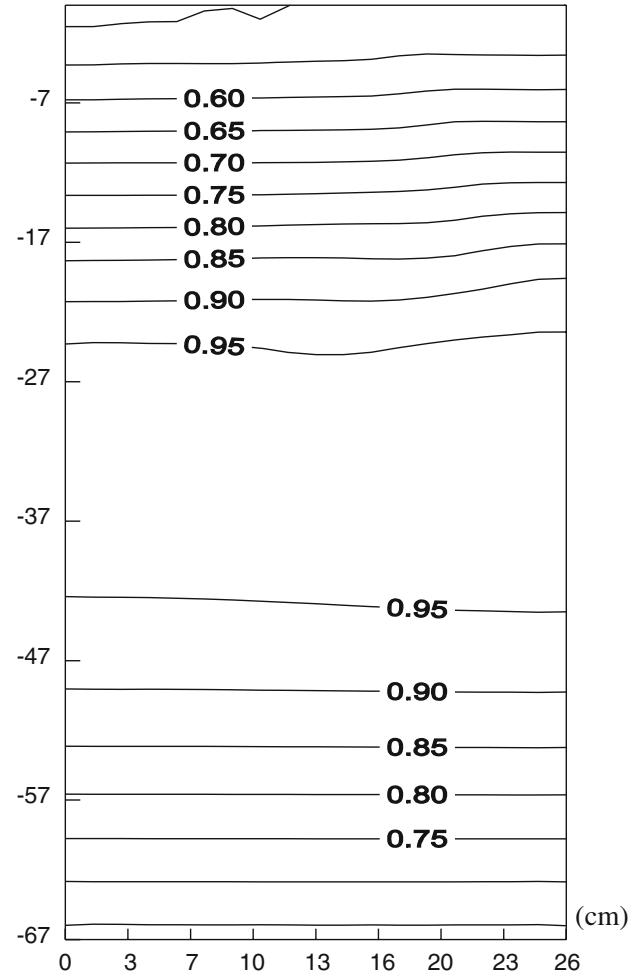

(c)

Fig. 11 Distribution of water saturation without hysteresis $(t-8,693 \mathrm{~s})$ and using G-DN (a), G-W (b), and DN-W (c) as reference pair

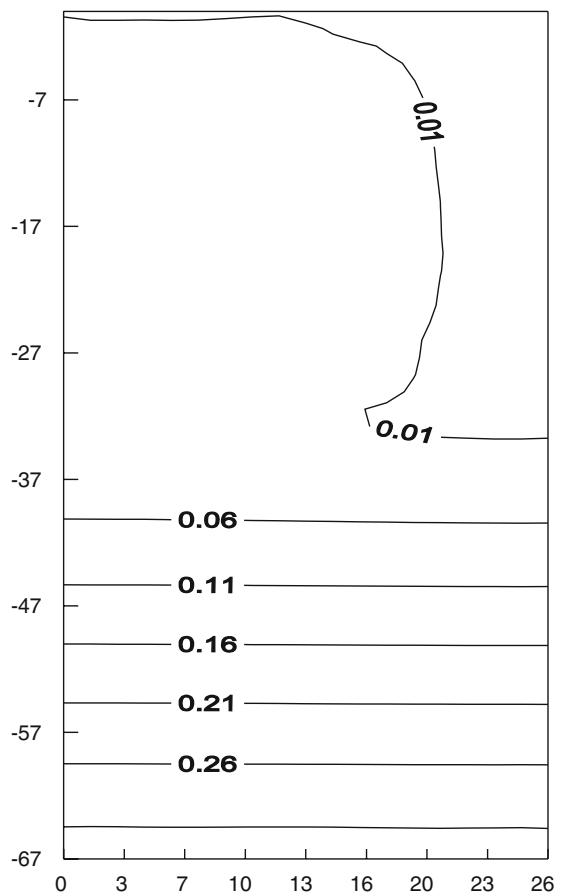

(a)

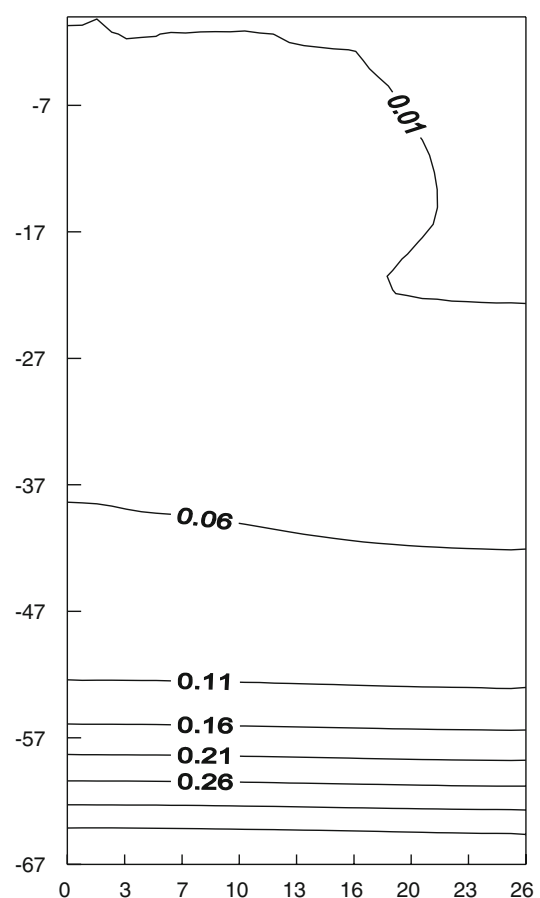

(b)

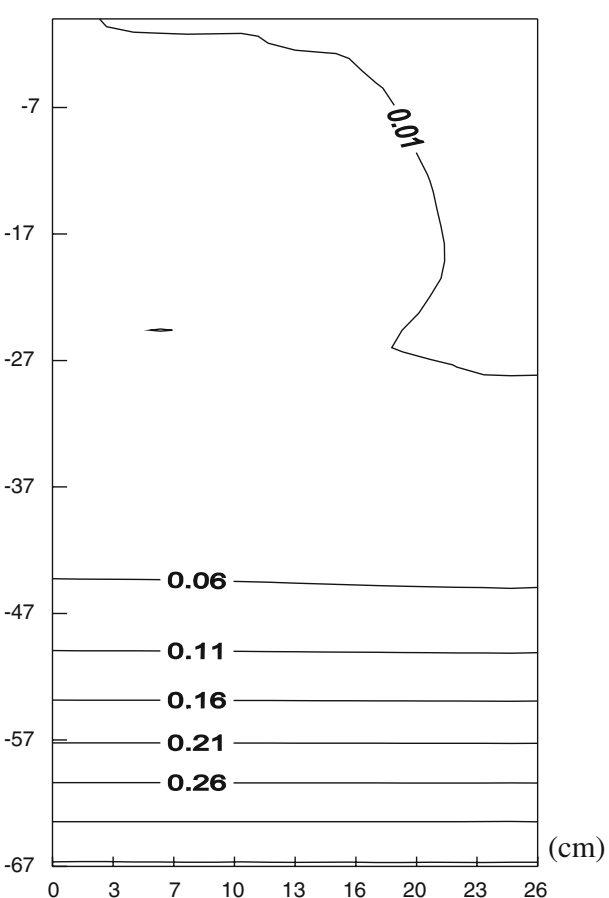

(c)

Fig. 12 Distribution of TCE saturation without hysteresis (t-8,693 s) and using G-DN (a), G-W (b), and DN-W (c) as reference pair 
hypothetical tank was much larger without hysteresis. The difference between the TCE mass with and without hysteresis was largest when TCE-air (DN-G) was used as the reference fluid pair. The TCE mass without hysteresis was $96.23 \%$ more than with hysteresis. Comparing Figs. 10, 11 , and 12 clearly demonstrates that the degree of saturation for TCE without hysteresis exceeds that with hysteresis, and the difference was largest when TCE-air (DN-G) was used as a reference pair. Moreover, as presented in Fig. 12, the invading front of TCE was wider without hysteresis. In this case, Table 10 also indicates that using water-TCE $(\mathrm{W}-\mathrm{G})$ as the reference pair yields the least difference $(14.63 \%)$ of the TCE mass with and without hysteresis. The difference $(18.82 \%)$ using water-air $(\mathrm{W}-\mathrm{G})$ pair was close to that using water-TCE (W-DN) pair.

According to the previous discussion, both gasoline and TCE infiltrated more into the hypothetic tank without hysteresis as revealed by the simulation. Before the NAPL infiltration, the water level in the tank was low and the upper part of the tank was an unsaturated zone filled with air and water. Hence, the infiltration of the NAPL proceeded mainly by imbibition, although it actually involved a complex multiphase flow of water, NAPL, and air.

\section{Conclusions}

This work examines the prediction accuracy of the scaling rule and the joint effect of hysteresis and the scaling rule on NAPL simulation for two NAPL multiphase systems water-gasoline-air and water-TCE-air. This investigation compares the predicted $P-S$ values computed by the scaling rule with the experimental ones and demonstrates that using the $P-S$ curve of water-air as the reference curve to predict the $P-S$ values of other fluid pairs minimizes the sum of root mean square deviations between the predicted and experimental values for both multiphase systems. Therefore, in predicting the $P-S$ value by the scaling rule, waterair fluid pair is preferred.

This investigation further explores the joint effect of hysteresis and the scaling rule based on NAPL simulation. The NAPL simulator was applied to examine the NAPL flow of two multiphase systems: water-gasoline-air and water-TCE-air. The simulation studies demonstrated two conclusions. First, the deviation of the infiltrating mass among different reference fluid pairs was significant for both LNAPL (gasoline) and DNAPL (TCE). This indicated that the NAPL flow simulation is sensitive to the reference $P-S$ curve. Selecting the reference $P-S$ curve is an important decision for characterizing the multiphase flow when employing the scaling rule in simulation. Another point is that for both gasoline and TCE, more mass leaked into the hypothetical tank without hysteresis. The situation is similar for using the water-air, water-NAPLs, or NAPLs-air as the reference fluid pairs. For gasoline, the infiltrating mass was $120 \%$ larger without hysteresis than with hysteresis; the maximum deviation for TCE was $96 \%$. This strongly demonstrates that the hysteresis effect cannot be neglected in the NAPL simulation.

\section{References}

1. Bedient, P. B., Rifai, H. S., \& Newell, C. J. (1994). Ground water contamination: Transport and remediation. Englewood Cliffs: Prentice Hall.

2. Fagerlund, F. F., Niemi, A., \& Oden, M. (2006). Comparison of relative permeability-fluid saturation-capillary pressure relations in the modeling of non-aqueous phase liquid infiltration in variably saturated, layered media. Advances in Water Resources, 29, 1705-1730. doi:10.1016/j.advwatres.2005.12.007.

3. Faust, C. R., \& Guswa, J. W. (1989). Simulation of threedimensional flow of immiscible fluids within and below the unsaturated zone. Water Resources Research, 25, 2449-2464. doi:10.1029/WR025i012p02449.

4. Flynn, D., McNamara, H., O'Kane, J. P., \& Pokrovskii, A. (2003). Application of the Preisach model to soil-moisture hysteresis. BCRI Preprint 15

5. Gen, M., \& Cheng, R. (1997). Genetic algorithms \& engineering design. New York: Wiley.

6. Guarnaccia, J. F., Pinder, G. F., \& Fishman, M. (1997). NAPL simulator documentation: Final Report EPA Cooperative Agreement No CR-820499.

7. Haverkamp, R., Reggiani, P., Ross, P. J., \& Parlange, J. Y. (2002). soil water hysteresis prediction model based on theory and geometric scaling. In P. A. C. Raats et al. (Eds.), Environmental mechanics: Water, mass and energy transfer in the biosphere (pp. 213-246). USA: American Geophysical Union.

8. Kaluarachchi, J., \& Parker, J. C. (1988). Effects of hysteresis on water flow in the unsaturated zone. Water Resources Research, 26, 223-245.

9. Kechavarzi, C., Soga, K., \& Illangasekare, T. H. (2005). Twodimensional laboratory simulation of LNAPL infiltration and redistribution in the vadose zone. Journal of Contaminant Hydrology, 76, 211-233. doi:10.1016/j.jconhyd.2004.09.001.

10. Kool, J. B., \& Parker, J. C. (1987). Development and evaluation of closed-form expressions for hysteresis soil hydraulic properties. Water Resources Research, 23, 105-114. doi:10.1029/WR023i $001 \mathrm{p} 00105$.

11. Kuppusamy, T., Sheng, J., Parker, J. C., \& Lenhard, R. J. (1987). Finite element analysis of Multiphase immiscible flow through soils. Water Resources Research, 23, 625-632. doi:10.1029/WR $023 \mathrm{i} 004 \mathrm{p} 00625$.

12. Land, C. S. (1968). Calculation of imbibition relative permeability for two- and three-phase flow from rock properties. Society of Petroleum Engineers Journal, 8, 149-156.

13. Lenhard, R. J., \& Parker, J. C. (1988). A model for hysteretic constitutive relations governing multiphase flow: 1. Saturationpressure relations. Water Resources Research, 23(12), 21872196.

14. Luckner, L., van Genuchten, M. T., \& Nielsen, D. R. (1989). A consistent set of parametric models for the two-phase flow of immiscible fluids in the subsurface. Water Resources Research, 25, 2187-2193. doi:10.1029/WR025i010p02187. 
15. Mercer, J. W., \& Cohen, R. M. (1990). A review of immiscible fluids in the subsurface properties models characterization and remediation. Journal of Contaminant Hydrology, 6, 107-163. doi:10.1016/0169-7722(90)90043-G.

16. Mualem, Y. (1984). A modified dependent-domain theory of hysteresis. Soil Science, 137, 283-291.

17. Parker, J. C., \& Lenhard, R. J. (1987). A model for hysteretic constitutive relations governing multiphase flow, 1. Saturationpressure relations. Water Resources Research, 23(12), 2187-2196.

18. Parker, J. C., Lenhard, R. J., \& Kuppusamy, T. (1987). A parametric model for constitutive properties governing multiphase flow in porous media. Water Resources Research, 23(4), 618-624. doi:10.1029/WR023i004p00618.

19. Parlange, J. Y. (1976). Capillary hysteresis and relationship between drying and wetting curves. Water Resources Research, 12, 224-228. doi:10.1029/WR012i002p00224.

20. Parlange, J. Y. (1980). Water transport in soils. Annual Review of Fluid Mechanics, 12, 77-102. doi:10.1146/annurev.fl.12.010180.000453.

21. Rojas, F., Kornhauser, I., Felipe, C., \& Cordero, S. (2001). Everett's sorption hysteresis domain theory revisited from the point of view of the dual site-bond model of disordered media. Journal of Molecular Catalysis A: Chemical, 167, 141-155. doi:10. 1016/S1381-1169(00)00501-X.

22. Rolston, D. E. (2007). Historical development of soil-water physics and solute transport in porous media. Water Science \& Technology: Water Supply l, 7(1), 59-66. doi:10.2166/ws.2007.007.

23. Shan, H. Y., \& Huang, J. F. (1998). Retention characteristics of water/hydrocarbon in sandy soils. Proceedings of the 13th Southeast Asian Geotechnical Conference, Taipei.

24. Van Geel, P. J., \& Roy, S. D. (2002). A proposed model to include a residual NAPL saturation in a hysteretic capillary pressuresaturation relationship. Journal of Contaminant Hydrology, 58, 79-110. doi:10.1016/S0169-7722(02)00012-8.

25. Van Genuchten, MTh. (1980). A closed form equation for predicting the hydraulic conductivity of unsaturated soils. Soil Science Society of America journal, 44, 892-898.

26. Zhang, Z. F., \& Smith, J. E. (2001). The velocity of DNAPL fingering in water-saturated porous media: Laboratory experiments and a mobile-immobile-zone model. Journal of Contaminant Hydrology, 49(3-4), 335-353. doi:10.1016/S0169-7722(01)00097-3. 